\title{
ASO Visual Abstract: Chemotherapy After Diagnosis of Malignant Bowel Obstruction is Associated with Greater Survival for Medicare Patients with Advanced Malignancy
}

Sarah B. Bateni, $\mathrm{MD}^{1}$, Alicia A. Gingrich, $\mathrm{MD}^{2}$, Amanda R. Kirane, $\mathrm{MD}^{2}$, Candice A. M. Sauder, $\mathrm{MD}^{2}$, Sepideh Gholami, $\mathrm{MD}^{2}$, Richard J. Bold, MBA, $\mathrm{MD}^{2}$, Frederick J. Meyers, $\mathrm{MD}^{3}$, and Robert J. Canter, $\mathrm{MD}^{2}$ (1)

${ }^{1}$ Division of Surgical Oncology, Department of Surgery, University of Toronto, Toronto, ON, Canada; ${ }^{2}$ Division of Surgical Oncology, Department of Surgery, Davis Medical Center, University of California, Sacramento, CA; ${ }^{3}$ Division of Hematology/Oncology, Department of Internal Medicine, Davis Medical Center, University of California, Sacramento, CA

In this SEER Medicare analysis (http://doi.org/10.124 5/s10434-021-09831-0), malignant bowel obstruction (MBO) management (surgery or medical) was not associated with subsequent chemotherapy. However, chemotherapy was associated with greater survival, suggesting chemotherapy plays an integral role in maximizing oncologic outcomes in select MBO patients.

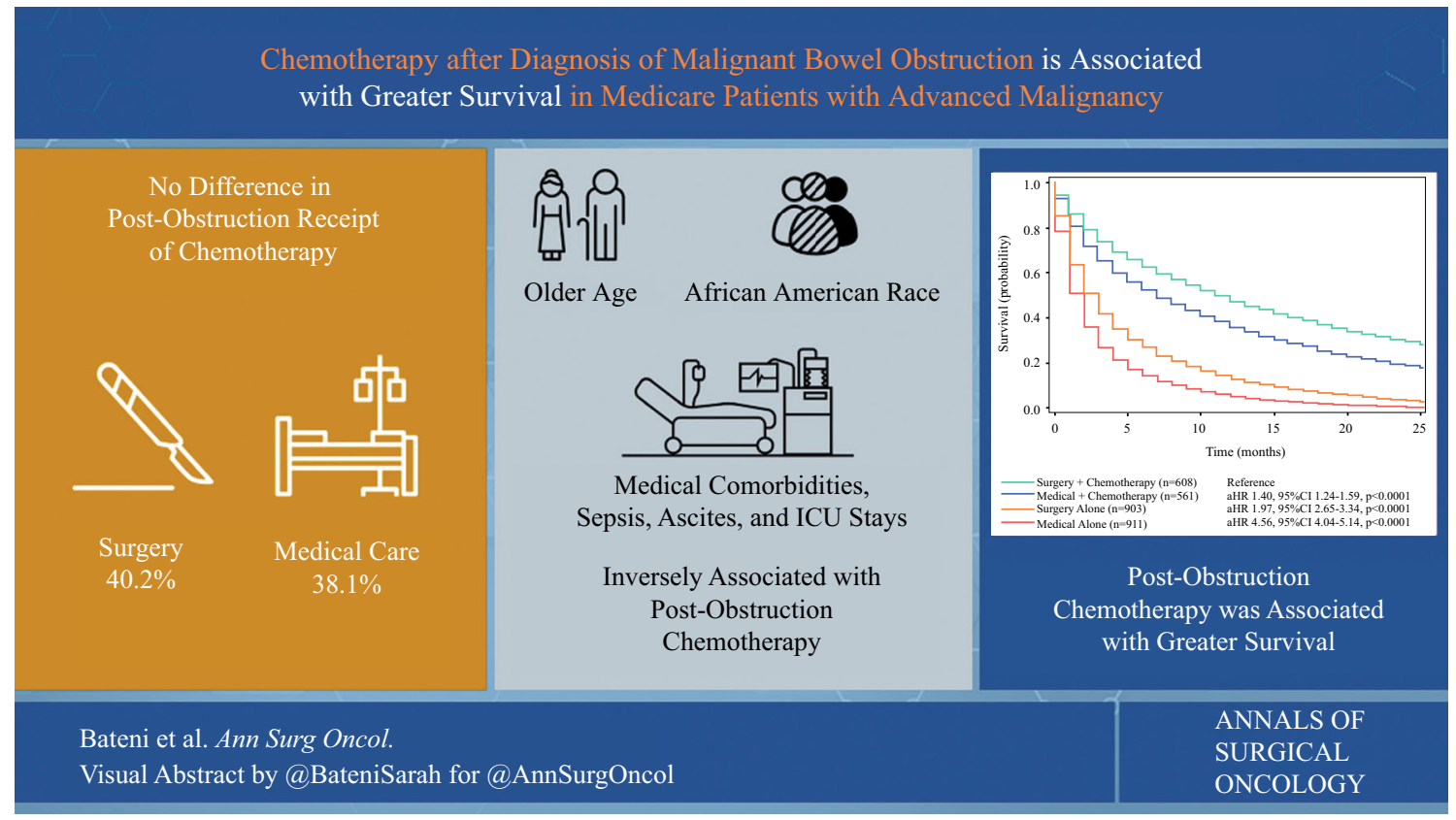

FUNDING This project was supported by the University of California Cancer Research Coordinating Committee (RJC, CTR\#-18524770).

DISCLOSURE There are no conflicts of interest.

(C) Society of Surgical Oncology 2021

Published Online: 12 May 2021

R. J. Canter, MD

e-mail: rjcanter@ucdavis.edu
Publisher's Note Springer Nature remains neutral with regard to jurisdictional claims in published maps and institutional affiliations. 